BMJ Open Diabetes

Research \& Care

\title{
Efficacy and safety of patient-led versus physician-led titration of basal insulin in patients with uncontrolled type 2 diabetes: a meta-analysis of randomized controlled trials
}

\author{
Marco Castellana (D) , ${ }^{1}$ Filippo Procino (D) , ${ }^{1}$ Rodolfo Sardone (D) , \\ Pierpaolo Trimboli (1) , 2,3 Gianluigi Giannelli (1) ${ }^{4}$
}

To cite: Castellana M, Procino F, Sardone R, et al. Efficacy and safety of patientled versus physician-led titration of basal insulin in patients with uncontrolled type 2 diabetes: a meta-analysis of randomized controlled trials. BMJ Open Diab Res Care 2020;8:e001477. doi:10.1136/ bmjdrc-2020-001477

- Additional material is published online only. To view please visit the journal online (http://dx.doi.org/10.1136/ bmjdrc-2020-001477).

Received 17 April 2020 Revised 26 May 2020 Accepted 2 June 2020
Check for updates

(C) Author(s) (or their employer(s)) 2020. Re-use permitted under CC BY-NC. No commercial re-use. See rights and permissions. Published by BMJ.

For numbered affiliations see end of article.

Correspondence to Dr Marco Castellana; mcastellana01@yahoo.it

\section{ABSTRACT}

Introduction Insulin is the most effective

antihyperglycemic treatment and basal insulin is the preferred initial formulation in patients with type 2 diabetes. However, its effects are dose-dependent, so adequate titration is necessary to reach targets. We performed a meta-analysis to compare the efficacy and safety of patient-led versus physician-led titration of basal insulin in patients with uncontrolled type 2 diabetes. Research design and methods Four databases were searched from database inception through March 2020. Randomized controlled studies with at least 12 weeks of follow-up of patients with type 2 diabetes allocated to patient-led versus physician-led titration of basal insulin were selected. Data on glycemic endpoints (hemoglobin A1c (HbA1c), fasting plasma glucose (FPG), hypoglycemia) and other outcomes (insulin dose, body weight, patientreported outcomes, adverse events, rescue medication, discontinuation) were extracted. Data were pooled using a random-effects model.

Results Six studies evaluating 12409 patients were finally included. Compared with the physician-led performance, patient-led titration was associated with a statistically significant higher basal insulin dose (+6 IU/ day), leading to benefits on $\mathrm{HbA1c}(-0.1 \%)$ and FPG $(-5 \mathrm{mg} / \mathrm{dL})$, despite a higher risk of any level hypoglycemia (relative risk=1.1) and a slight increase in body weight $(+0.2 \mathrm{~kg})$. No difference was found for the other outcomes. Conclusions The present study showed that patient-led titration of basal insulin was not inferior to physician-led titration in patients with uncontrolled type 2 diabetes. Therefore, diabetes self-management education and support programs on basal insulin should be widely adopted in clinical practice and patients provided with tools to self-adjust their dose when necessary.

\section{INTRODUCTION}

Diabetes is a complex, chronic disease characterized by high prevalence, morbidity, and excess mortality. It is associated with multiple complications and comorbidities, including overweight and obesity, cardiovascular disease, kidney failure, blindness,

\section{Significance of this study}

What is already known about this subject?

- Basal insulin is the preferred initial formulation in patients with uncontrolled type 2 diabetes; since the improvements in glycemic control that can be achieved with these agents are dose-dependent, adequate titration is key to achieving targets.

- Whether the titration of basal insulin performed by the patient is associated with similar outcomes compared with dose adjustments performed by the physician is unclear.

What are the new findings?

- Compared with the physician-led performance, patient-led titration was associated with a higher daily basal insulin dose, leading to a statistically significant but not clinically relevant advantage in terms of hemoglobin A1C and fasting plasma glucose, together with a limited increase in the risk of any level hypoglycemia and a slight body weight increase.

- No differences were found for risk of level 3 hypoglycemia, requiring rescue medication, discontinuation, adverse events or patient-reported outcomes.

- No heterogeneity was found for six out of eight outcomes, confirming the robustness of findings regardless of the characteristics of included patients, the concomitant therapy and the algorithm for titration of basal insulin.

How might these results change the focus of research or clinical practice?

- In patients with uncontrolled type 2 diabetes, our findings indicate that patient-led titration should be regarded as not inferior to basal insulin dose adjustments performed by physicians, and acknowledged as an adequate strategy to be widely adopted in clinical practice.

non-alcoholic fatty liver disease and cognitive impairment. $^{1-4}$ Timely diagnosis, effective therapy and follow-up reduce the burden 
of the disease, as well as its economic impact on people with diabetes, their families, and the healthcare system. ${ }^{1}$ Therefore, the definition of a management plan based on lifestyle modifications, medications and other intervention (eg, bariatric surgery), when needed, is strongly recommended. ${ }^{2}$

It is common knowledge that type 2 diabetes is often characterized by a progressive clinical course. Indeed, concerning pharmacologic therapy, patients are generally started on metformin monotherapy, then a shift to dual/triple combination therapy often becomes necessary to maintain glycemic targets. ${ }^{5}$ The choice of additional drugs should be made taking into account patient preference and clinical characteristics, including the presence of indicators of a high risk or history of cardiovascular disease, heart failure or chronic kidney disease. ${ }^{6-8}$ However, the definition of diabetes is based on hyperglycemia, and glycemic management aiming at blood glucose concentrations close to the normal range has been shown to reduce the incidence and progression of complications, both microvascular and possibly macrovascular. ${ }^{9}$ Therefore, together with the above-mentioned issues and the impact on body weight, risk of hypoglycemia, tolerability and costs, the glucose-lowering power of each drug must always be considered, too. Insulin is the most effective antihyperglycemic treatment and basal insulin is the preferred initial formulation in patients with type 2 diabetes. ${ }^{5}$ It can be introduced early in patients with very high hemoglobin A1c (HbA1c) levels $(>10 \%$; $86 \mathrm{mmol} / \mathrm{mol}$ ), symptoms of hyperglycemia, or evidence of ongoing catabolism (eg, weight loss), or added to any other available drug, if further intensification is needed. ${ }^{5}$ It is important to note that the improvements in glycemic control that can be achieved with basal insulin are dosedependent. ${ }^{6}$ On one hand, it follows that insulin can lower glucose over a wide range, to almost any glycemic target as limited by hypoglycemia. On the other hand, the goals can be achieved only thanks to adequate titration, performed either by the patient or by the physician. ${ }^{56}$

Despite polytherapy, glycemic targets are not achieved in a large proportion of people with type 2 diabetes. ${ }^{10-12}$ Different factors may play a role, including therapeutic inertia, limited adherence and the progressively increasing discrepancy between the burden of this disorder and the healthcare resources. ${ }^{12}$ Diabetes selfmanagement education and support is key for patient empowerment, in terms of informed decision-making, self-care behavior, problem-solving, and active collaboration with the healthcare system. ${ }^{13}$ This approach has been shown to reduce the risk of all-cause mortality in patients with type 2 diabetes. ${ }^{14}$ In an insulin perspective, the patient is provided with tools to adjust the daily dose when necessary. Remarkable numbers of patients are currently using basal insulin, but a high level of evidence on the results and implications of patient self-adjustments is currently lacking. Therefore, we conducted the present study to achieve solid information on the efficacy and safety of patient-led versus physician-led titration of basal insulin in patients with uncontrolled type 2 diabetes. A systematic search was carried out to identify randomized controlled trials (RCT) on the topic. We also performed a meta-analysis of the available data, comparing the two options in terms of (1) glycemic endpoints, including HbAlc, fasting plasma glucose (FPG), and hypoglycemia; and (2) other outcomes, including daily basal insulin dose, body weight, patient-reported outcomes, adverse events, initiation of rescue medication, and discontinuation.

\section{METHODS}

The meta-analysis was registered in PROSPERO (International Prospective Register of Systematic Reviews; CRD42020176794) and performed in accordance with the Preferred Reporting Items for Systematic Reviews and Meta-Analyses statement (online supplementary table S1). ${ }^{15}$

\section{Data sources and searches}

A five-step research strategy was drawn up. First, we searched for sentinel studies in PubMed. Second, we identified keywords in PubMed. Third, the terms "diabetes", "insulin", "titration", "investigator" and "physician" were researched on PubMed to test the strategy. Fourth, CENTRAL, Scopus and Web of Science were researched using the same strategy. Lastly, references of the included studies were searched to find additional papers. The last search was performed on March 28, 2020. No language restriction was adopted. Two investigators (MC, FP) independently searched for papers, screened titles and abstracts of the retrieved articles, reviewed the full texts, and selected the articles for inclusion.

\section{Study selection}

RCTs with at least 12 weeks of follow-up of patients with type 2 diabetes randomized to patient-led or physician-led titration of basal insulin were selected. Studies were excluded if (1) based on insulin other than degludec, detemir, glargine U-100 or glargine U-300; (2) based on the simultaneous titration of prandial and basal insulin; and (3) titration in the patient-led arm was performed using technology (eg, devices, web tools, smartphone applications, or text messages).

\section{Data extraction and quality assessment}

The following information was extracted independently by the same investigators in a piloted form: (1) general information on the study (author, year of publication, country, study type, follow-up period, inclusion criteria, number of patients, characteristics of patients at baseline); (2) algorithms for titration of basal insulin in the patient-led and physician-led arms; (3) glycemic endpoints, including HbA1c, FPG and number of patients with at least one hypoglycemic event; (4) daily basal insulin dose; (5) body weight; (6) patientreported outcomes; (7) adverse events; (8) number of patients requiring rescue medication; and (9) number 
of discontinuations. For hypoglycemia, separate analyses were performed for any event and severe events requiring assistance for treatment only (level 3 hypoglycemia). ${ }^{9}$ The main paper and supplementary data were examined. Data were cross-checked, and any discrepancy was discussed.

The risk of bias of the included studies was assessed independently by two reviewers (MC, FP) according to The Cochrane Collaboration tool. The following aspects were evaluated: random sequence generation; allocation concealment; blinding of participants and personnel; blinding of outcome assessment; incomplete outcome data; and selective reporting. Regarding other bias, funding was assessed. Each domain was assigned a low, unclear or high risk of bias. ${ }^{16}$

\section{Data synthesis and analysis}

The primary outcome was the difference in change in HbA1c from baseline to the last available follow-up between the patient-led and the physician-led titration of basal insulin. Secondary outcomes included differences in (1) change in FPG, daily basal insulin dose, and body weight; (2) number of patients with at least one hypoglycemic event, number of patients requiring rescue medication and number of discontinuations; and (3) patient-reported outcomes and adverse events. Endpoints were analyzed as (1) continuous variables and summarized as weighted mean difference and (2) dichotomous variables, and the relative risk (RR) was estimated. For the third endpoints, we only collected data in tables, given the heterogeneous reporting. If SD was missing in a study for a specific outcome, it was calculated from SE or $95 \%$ CI; if none of these was available, the largest value among the other studies was assigned. Pooled data were presented with $95 \%$ CI. Heterogeneity between studies was assessed using $\mathrm{I}^{2}$, with $50 \%$ or higher being regarded as high. Publication bias was assessed with Egger's test; the trim-and-fill method was used to estimate its effect. All analyses were two-sided and were carried out using RevMan V.5.3 (The Cochrane Collaboration) and Prometa V.3.0 (Internovi) with a random-effect model. Significance was set at $\mathrm{p}<0.05$.

\section{RESULTS}

\section{Study characteristics}

In total, 331 papers were found, 36 of which were on PubMed, 138 on CENTRAL, 115 on Scopus, and 42 on Web of Science. After removing 106 duplicates, title and abstract of 225 articles were analyzed; 196 records were excluded (review; study protocol; not titration strategies; titration performed using technology; insulin other than detemir, degludec, glargine U-100 or glargine U-300; titration of prandial insulin only or simultaneous titration of prandial and basal insulin; not within the scope of the meta-analysis). The remaining 29 papers were retrieved in full text and 6 studies were finally included in the meta-analysis (figure 1). ${ }^{17-22}$ No additional study was retrieved from the references of included studies.

\section{Study quality assessment}

The risk of bias of the included studies is shown in online supplementary table S2. Information on random sequence generation was not reported in any study, while a central allocation was reported only in three. ${ }^{19} 2122$ Blinding of participants and personnel and blinding of outcome assessment bias were rated as low: studies were open-label, so there could have been a high risk of performance and detection bias, but no other study design could have been used since basal insulin needs to be

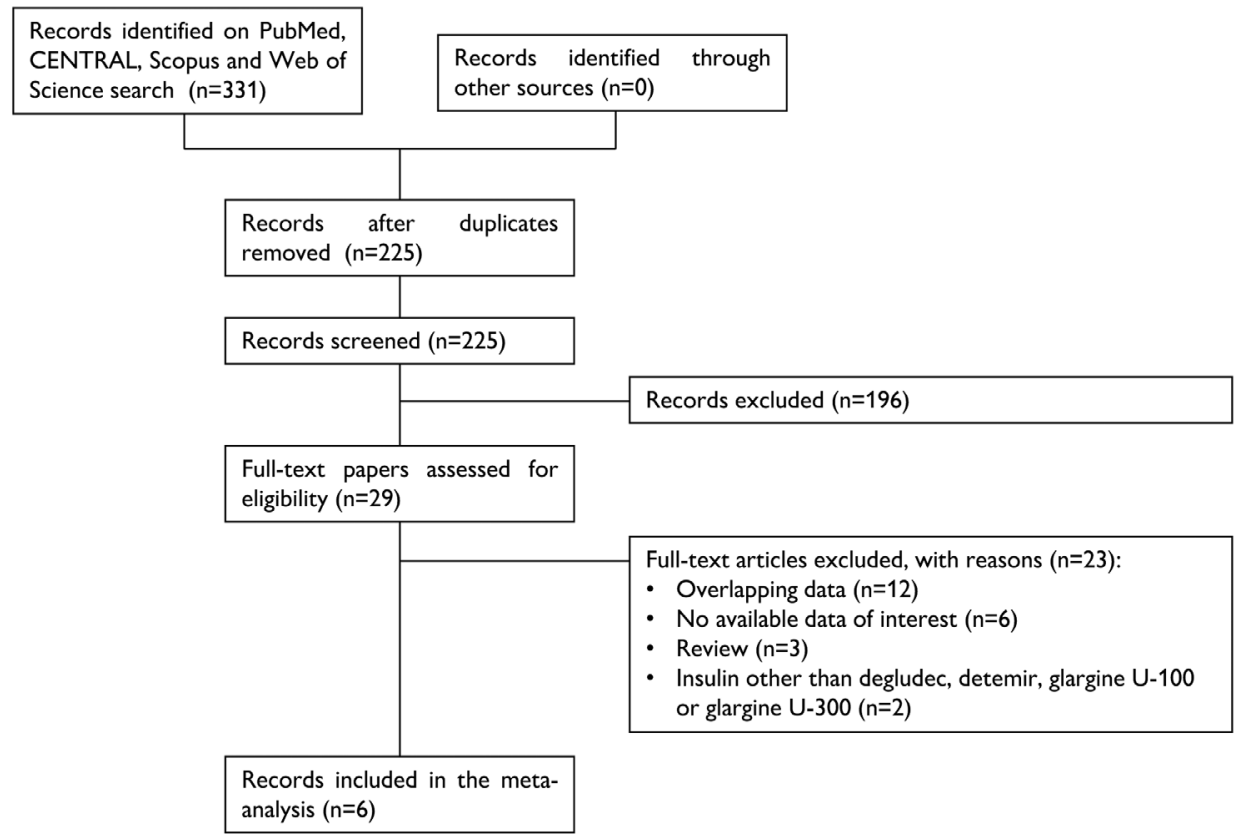

Figure 1 PRISMA flow diagram. PRISMA, Preferred Reporting Items for Systematic Reviews and Meta-Analyses. 
titrated. As regards incomplete outcome data bias, all studies reported a similar discontinuation rate in the two arms. All of the studies' prespecified outcomes were reported in the prespecified way. Finally, an industrial sponsor funded all the studies. ${ }^{17-22}$

\section{Qualitative analysis}

The characteristics of the included articles are summarized in table $1 .{ }^{17-22}$ The studies were published between 2005 and 2020, had sample sizes ranging from 212 to 5619 patients, and with follow-up ranging from 12 to 26 weeks. All studies were RCTs. Three studies were multinational, one was conducted in Canada, one in Italy and one in the USA. Three studies used glargine U-300 as basal insulin, two glargine U-100, and one detemir. Data on target FPG, frequency of titration and titration algorithms are reported in online supplementary table S3. Participants were adult outpatients diagnosed with type 2 diabetes, with an $\mathrm{HbAlc}$ from $7 \%$ to $12 \%$ (53-108 $\mathrm{mmol} / \mathrm{mol}$ ), insulin-naive or insulin-treated. Overall, 12409 patients were included; $51 \%$ were men, the weighted mean age was $58.6 \pm 10.9$ years, and the weighted mean baseline HbAlc was $8.7 \pm 1.4 \%$. Of these, 6174 were allocated to patient-led titration of basal insulin and 6235 to physician-led.

\section{Quantitative analysis}

The primary outcome was the difference in change in HbA1c from baseline to the last available follow-up. Compared with physician-led performance, patient-led titration of basal insulin was associated with an additional reduction in $\mathrm{HbAlc}$ by $-0.12 \%$ (95\% CI -0.16 to -0.07 ; $\mathrm{I}^{2}=0 \%$ ) (figure 2A). In line with this, patients allocated to this treatment were characterized by a lower FPG $\left(-5.2 \mathrm{mg} / \mathrm{dL} ; 95 \% \mathrm{CI}-9.3\right.$ to $\left.-1.2 ; \mathrm{I}^{2}=59 \%\right)$ (figure $2 \mathrm{~B}$ ) and a higher daily basal insulin dose $(5.9 \mathrm{IU} /$ day; $95 \% \mathrm{CI}$ 0.2 to $11.8 ; \mathrm{I}^{2}=92 \%$ ) (online supplementary figure $\mathrm{S} 1$ ). As to the incidence of hypoglycemic events, patient-led titration was associated with a higher risk of any level hypoglycemia ( $R R=1.12 ; 95 \%$ CI 1.02 to $\left.1.23 ; I^{2}=18 \%\right)$, despite a similar risk of level 3 episodes ( $R R=1.20 ; 95 \%$ CI 0.73 to $1.98 ; \mathrm{I}^{2}=0 \%$ ) (figure 3).

Patient-led titration was also associated with a higher body weight by $0.25 \mathrm{~kg}$ (95\% CI 0.06 to $0.44 ; \mathrm{I}^{2}=0 \%$ ) (online supplementary figure S2). No differences in risk of requiring rescue medication, risk of discontinuation or patient-reported outcomes were found. In Yale $e t a l,{ }^{20}$ a higher satisfaction was reported by healthcare professionals for the patient-led algorithm (online supplementary figures S3 and S4 and online supplementary table S4). No drug-related serious adverse event was reported, while a similar frequency of drug-related treatmentemergent adverse events was reported in the two study arms (data not shown).

There was no evidence of publication bias (online supplementary table S5).

\section{DISCUSSION}

The aim of this meta-analysis was to identify the best available evidence of the efficacy and safety of patient-led versus physician-led titration of basal insulin in patients with uncontrolled type 2 diabetes. Six RCTs were found, with a follow-up ranging from 12 to 26 weeks, evaluating 12409 adult insulin-naive or insulin-treated patients with HbAlc between $7 \%$ and $12 \%$ (53 and $108 \mathrm{mmol} / \mathrm{mol}$ ). The overall results of our meta-analysis showed a higher efficacy of the patient-led strategy on HbAlc, FPG and daily basal insulin dose. However, patients allocated to this arm showed a higher body weight and risk of any level hypoglycemia. No differences were found for risk of level 3 hypoglycemia, requiring rescue medication, discontinuation, adverse events or patient-reported outcomes. Also, no heterogeneity was found for six out of eight outcomes, confirming the robustness of our findings regardless of the characteristics of included patients, the concomitant therapy and the algorithm for titration of basal insulin. To our knowledge, this is the first metaanalysis on the topic. Papers were searched without time restrictions and inclusion criteria were defined prior to the database searches. We believe this to be a significant contribution to the current understanding in this field, since studies evaluating populations from different countries with different inclusion criteria and protocols could thus be interpreted together.

The algorithms adopted differed among the studies. First, the same FPG level or range was targeted in both arms of each study. However, it varied from $\leq 100 \mathrm{mg}$ / $\mathrm{dL}$ FPG in Davies et $a l^{17}$ to $80-130 \mathrm{mg} / \mathrm{dL}$ FPG in Russell-Jones at al, ${ }^{21}$ being $110 \mathrm{mg} / \mathrm{dL}$ or $80-100 \mathrm{mg} /$ $\mathrm{dL}$ or $80-110 \mathrm{mg} / \mathrm{dL}$ in the other studies. Second, basal insulin was titrated more frequently in the patient-led arm, as expected. Particularly, titration was performed every 3-4 days by patients versus weekly at most by physicians. The only exception was Yale et $a l^{20}{ }^{20}$ where the patients increased the insulin dose by $+1 \mathrm{IU} /$ day, whereas physician-titrated insulin was done at least once weekly but not more often than once every 3 days. ${ }^{20}$ Third, three studies reported similar dose adjustment by both patients and physicians, ${ }^{1921} 22$ while a more aggressive titration was reported in the physician-led arm in two studies. ${ }^{1720}$ In Meneghini $e a^{18}$ a comparison could not be performed because only a reference to the standard-of-care practice was made for the physician-led algorithm. Despite these differences, patient-led titration was consistently associated with a higher daily basal insulin dose, leading to improved HbAlc and FPG. Therefore, regardless of the method adopted in each study, significant benefits can be achieved by means of patient training on how to perform titration of basal insulin, even when compared with dose adjustments performed by physicians in an RCT setting. It is important to note that, while the frequency of patient-led adjustments seems to be reasonable and sustainable also in a real-life setting and for periods longer than the duration of the included studies, the same does not hold true for physician-led adjustments. The discrepancies between RCT and real-world findings reported for several interventions, showing that the former results were not found to be replicable in the latter setting, may 


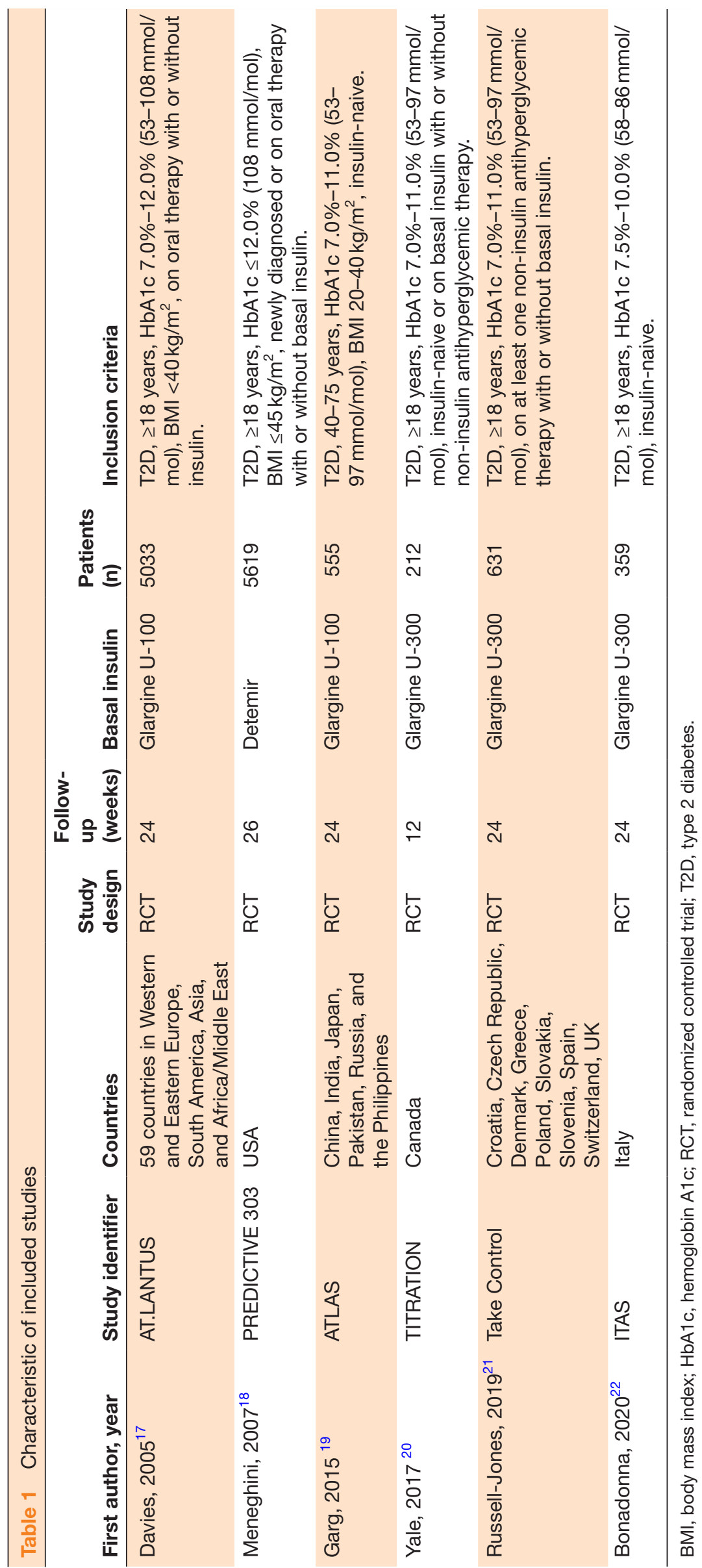




\begin{tabular}{|c|c|c|c|c|c|c|c|c|c|c|c|c|}
\hline \multirow{2}{*}{$\begin{array}{l}\text { A } \\
\text { Study }\end{array}$} & \multicolumn{3}{|c|}{ Patient-led } & \multicolumn{3}{|c|}{ Physician-led } & \multirow[b]{2}{*}{ Weight } & \multicolumn{2}{|l|}{ Mean Difference } & \multirow{2}{*}{\multicolumn{2}{|c|}{$\begin{array}{c}\text { Mean Difference } \\
\text { IV, Random, } 95 \% \text { Cl }\end{array}$}} & \\
\hline & Mean & SD & Total & Mean & SD & Total & & IV, Random, $95 \% \mathrm{Cl}$ & & & & \\
\hline Bonadonna 2020 & -1.6 & 0.79 & 175 & -1.49 & 0.8 & 180 & $7.4 \%$ & $-0.11[-0.28,0.06]$ & & & & \\
\hline Davies 2005 & -1.22 & 1.26 & 2273 & -1.08 & 1.27 & 2315 & $37.6 \%$ & $-0.14[-0.21,-0.07]$ & & - - & & \\
\hline Garg 2015 & -1.4 & 1.26 & 275 & -1.25 & 1.27 & 277 & $4.5 \%$ & $-0.15[-0.36,0.06]$ & & & & \\
\hline Meneghini 2007 & -0.6 & 1.21 & 2157 & -0.5 & 1.21 & 2158 & $38.6 \%$ & $-0.10[-0.17,-0.03]$ & & - & & \\
\hline Russell-Jones 2019 & -0.97 & 0.94 & 314 & -0.84 & 0.93 & 317 & $9.5 \%$ & $-0.13[-0.28,0.02]$ & & & & \\
\hline Yale 2017 & -0.8 & 1.1 & 108 & -0.8 & 1 & 104 & $2.5 \%$ & $0.00[-0.28,0.28]$ & & & & \\
\hline Total $(95 \% \mathrm{Cl})$ & & & 5302 & & & 5351 & $100.0 \%$ & $-0.12[-0.16,-0.07]$ & & & & \\
\hline $\begin{array}{l}\text { Heterogeneity: } \text { Tau }^{2} \\
\text { Test for overall effec }\end{array}$ & $\begin{array}{l}0.00 ; \mathrm{Cl} \\
\mathrm{Z}=5.17\end{array}$ & $\begin{array}{l}i^{2}=1 . \\
(P<C\end{array}$ & $\begin{array}{l}38, \mathrm{df}= \\
.00001\end{array}$ & $5(P=$ & & $=0 \%$ & & & -0.5 & $\begin{array}{l}-0.25 \\
\text { ors patient-led }\end{array}$ & $\begin{array}{lr}0 & 0.2 \\
& \text { Favors phy }\end{array}$ & led 0.5 \\
\hline
\end{tabular}

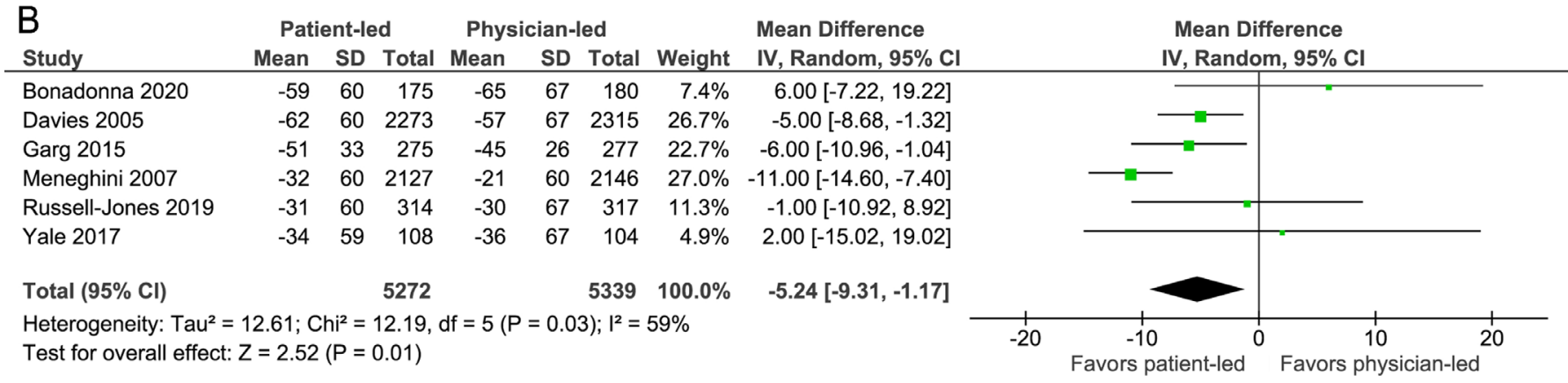

Figure 2 Forest plot of meta-analysis for difference in change in hemoglobin A1c (A) and fasting plasma glucose (B) from baseline to the last available follow-up on patient-led versus physician-led titration of basal insulin. IV, inverse variance.

possibly have a less relevant role in this context as long as training sessions are planned and can be repeated as often as necessary until patients can demonstrate competent unaided use. ${ }^{212324}$

When the statistical significance is met for a specific outcome, the clinical relevance of that finding should also be assessed. Compared with the physician-led performance, patient-led titration was found to be associated with absolute differences in change in $\mathrm{HbAlc}$ by $-0.1 \%$,
FPG by $-5 \mathrm{mg} / \mathrm{dL}$, body weight by $+0.2 \mathrm{~kg}$ and risk of any level hypoglycemia by 1.1. The clinical implications of these findings may be limited. Therefore, from a clinical perspective, patient-led titration should be regarded as at least non-inferior to basal insulin dose adjustment performed by the physician. The only exception could be for the difference in change in daily basal insulin dose (+6IU/day), corresponding to about $+15 \%$ of the daily basal insulin dose in the physician-led arm at the last

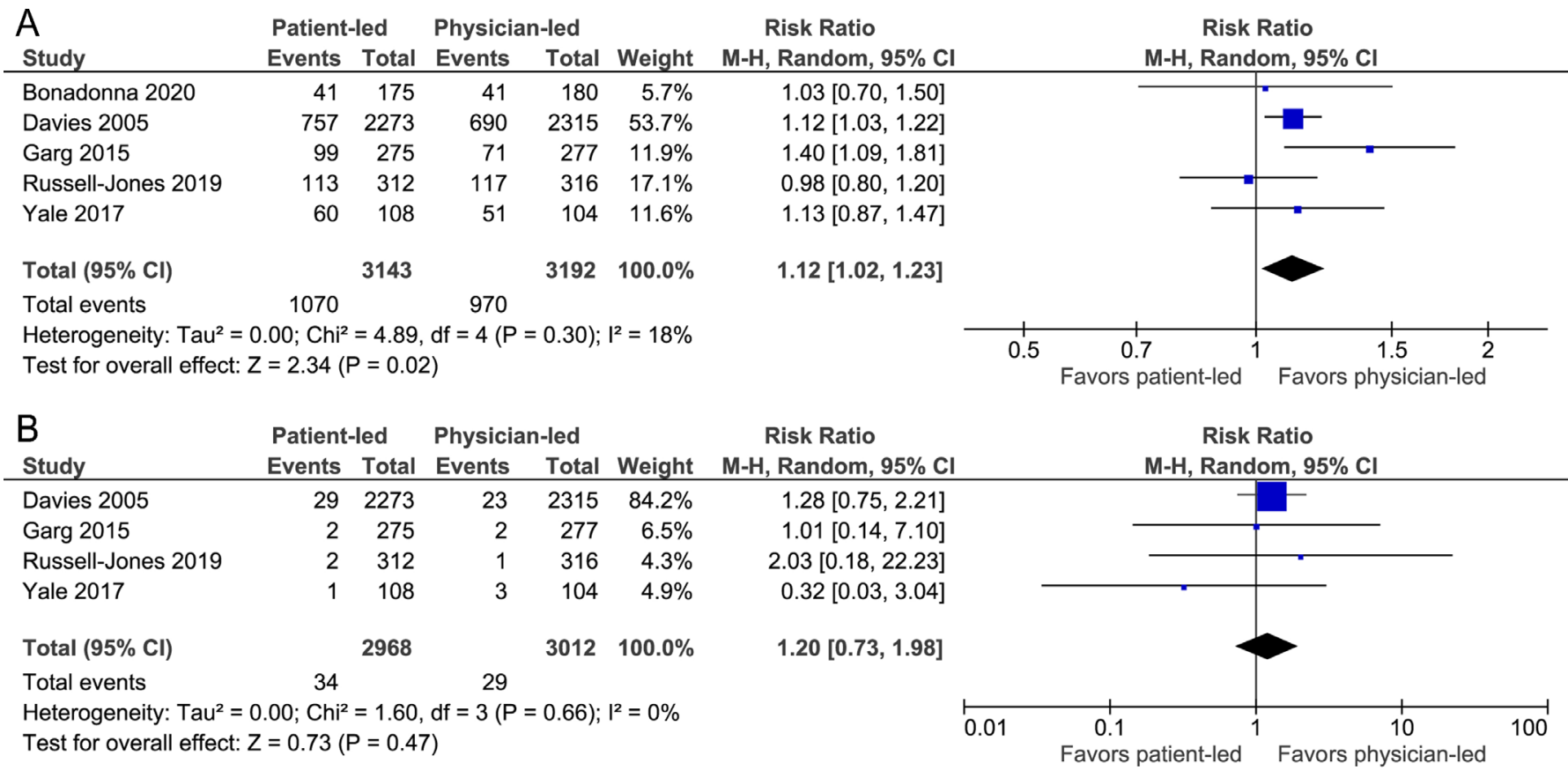

Figure 3 Forest plot of meta-analysis for relative risk of any level hypoglycemia $(A)$ and level 3 hypoglycemia (B) on patientled versus physician-led titration of basal insulin. $\mathrm{M}-\mathrm{H}$, Mantel-Haenszel. 
available follow-up (44IU/day). Interestingly, no differences were found for patient-reported outcomes, adverse events, rescue medication or discontinuation; therefore, no reduced treatment compliance has to be expected when patients are directly involved in managing their basal insulin dose. ${ }^{20}$

This raises the question as to whether one specific patient-led algorithm for titration of basal insulin should be preferentially used in clinical practice. Because there was no heterogeneity of findings for our primary outcome (eg, HbAlc), no recommendation can be based on our data. The ideal titration algorithm should be simple to ensure patient compliance, effective to allow targets to be reached, and safe to minimize the risk of hypoglycemia. First, the target to be reached should be defined. A study compared two patient-led titration algorithms using detemir in insulin-naive patients with type 2 diabetes. Compared with $80-110 \mathrm{mg} / \mathrm{dL}$, an FPG range of $70-90 \mathrm{mg} / \mathrm{dL}$ was found to be more effective on HbAlc and associated with a comparable rate of hypoglycemia. ${ }^{25}$ Possibly, the lower half of the premeal glucose target of $80-130 \mathrm{mg} / \mathrm{dL}$ recommended by the American Diabetes Association should be targeted, as long as it can be achieved without an increased risk of hypoglycemia. ${ }^{9}$ Second, the dose adjustments (and frequency) should be defined. A study compared two algorithms using degludec in insulin-naive patients with type 2 diabetes. No difference was found between two once-weekly dose adjustments, namely a less aggressive titration based on a single pre-breakfast glycemia or a more aggressive titration based on the lowest value of three consecutive days' pre-breakfast glycemias. ${ }^{26}$ Similar findings were recently reported in another study in insulin-naive patients with type 2 diabetes treated with detemir. ${ }^{27}$ Third, it is important to decide whether training should be delivered in groups or individually, although one study found no difference between the two approaches. ${ }^{28}$ Overall, current literature does not support the use of a specific algorithm that should be selected based on individual patient characteristics, type of basal insulin and goals.

Limitations of the present paper should be discussed. First, a limited number of studies, usually with shortterm follow-up, were found. Specifically, we were able to find data related to six studies in which patients were only followed up to 26 weeks. In addition, patients had an $\mathrm{HbA1c}$ at baseline ranging between $7 \%$ and $12 \%$ (53 and $108 \mathrm{mmol} / \mathrm{mol}$ ), and some studies limited enrollment to patients with a maximum HbAlc of $10 \%$ (86 $\mathrm{mmol} / \mathrm{mol}$ ). Whether the inclusion of patients with higher HbA1c levels or followed up for longer periods would have led to different results remains to be assessed. Five of six studies used glargine, either U-100 or U-300, as basal insulin and one used detemir, while no study using degludec was found, and this is a second limitation. Indeed, all included studies using detemir or glargine reported similar findings, including a higher daily basal insulin dose in the patient-led titration arm, either statistically significant or not; however, the latter basal insulin is characterized by different pharmacokinetic and pharmacodynamic profiles. ${ }^{29}$ Third, it is common knowledge that RCTs are generally developed to assess the efficacy and safety of a therapeutic agent or strategy under ideal conditions. Specifically, the frequency of visits/contacts/calls is higher than can generally be assured in clinical practice. ${ }^{30}$ Caution should thus be employed when generalizing these results to clinical practice. Lastly, studies assessing patient-led titration of basal insulin using technology are available in the literature, and a good efficacy/safety profile is being reported for this intervention, too. Compared with the physician-led performance, technology-supported patient-led titration was found to be associated with an earlier but similar change in HbA1c in one study. ${ }^{31}$ Compared with standard patient-led titration, technological support was found to be associated with similar outcomes in one study or even an earlier decline and greater reduction in another study. ${ }^{323}$ Preliminary results are interesting, but the limited number of patients studied and the heterogeneity among interventions call for further research on this topic. In summary, all available options should always be discussed with the patient, the key role of glucose monitoring addressed, and a shared decision made about whether adjustments of basal insulin should be predominantly patient-led (following adequate training with or without technological support) or physician-led. Also, the insulin therapy should always be included in a full care program, based on lifestyle measures first, and tackling all the components of the metabolic syndrome.

In patients with uncontrolled type 2 diabetes for whom basal insulin is indicated, adequate titration is key to achieving the target HbA1c without hypoglycemic events. Compared with the physician-led performance, patient-led titration was associated with a higher daily basal insulin dose, leading to a statistically significant but not clinically relevant advantage in terms of $\mathrm{HbAlc}$ and FPG, together with a limited increase in the risk of any level hypoglycemia and a slight body weight increase. Therefore, patient-led titration should be regarded as not inferior to basal insulin dose adjustments performed by physicians, and acknowledged as an adequate strategy to be widely adopted in clinical practice. Further studies comparing the two strategies are needed to fully assess potential differences in long-term outcomes.

\section{Author affiliations}

${ }^{1}$ Population Health Unit, National Institute of Gastroenterology "Saverio de Bellis", Research Hospital, Castellana Grotte, Italy

${ }^{2}$ Clinic of Endocrinology and Diabetology, Lugano and Mendrisio Regional Hospital, Ente Ospedaliero Cantonale, Lugano, Switzerland

${ }^{3}$ Faculty of Biomedical Sciences, Università della Svizzera Italiana (USI), Lugano,

Switzerland

${ }^{4}$ Scientific Direction, National Institute of Gastroenterology "Saverio de Bellis", Research Hospital, Castellana Grotte, Italy

Acknowledgements The authors thank Mary VC Pragnell, BA (Monopoli, Italy) for editing.

Contributors MC conceived the meta-analysis. MC and FP developed the search strategy and provided statistical expertise. MC drafted the manuscript. All authors 
contributed to the development of the selection criteria, the risk of bias assessment strategy and data extraction criteria. All authors read, provided feedback, and approved the final manuscript. MC is the guarantor and takes responsibility for the content of the article.

Funding The authors have not declared a specific grant for this research from any funding agency in the public, commercial or not-for-profit sectors.

Competing interests None declared.

Patient consent for publication Not required.

Ethics approval This meta-analysis was in accordance with the principles of the Declaration of Helsinki. Analyses were performed on data extracted from published papers.

Provenance and peer review Not commissioned; externally peer reviewed.

Data availability statement The data sets generated and/or analyzed during the current study are not publicly available but are available from the corresponding author on reasonable request.

Open access This is an open access article distributed in accordance with the Creative Commons Attribution Non Commercial (CC BY-NC 4.0) license, which permits others to distribute, remix, adapt, build upon this work non-commercially, and license their derivative works on different terms, provided the original work is properly cited, appropriate credit is given, any changes made indicated, and the use is non-commercial. See: http://creativecommons.org/licenses/by-nc/4.0/.

\section{ORCID iDs}

Marco Castellana http://orcid.org/0000-0002-1175-8998

Filippo Procino http://orcid.org/0000-0003-2740-2547

Rodolfo Sardone http://orcid.org/0000-0003-1383-1850

Pierpaolo Trimboli http://orcid.org/0000-0002-2125-4937

Gianluigi Giannelli http://orcid.org/0000-0002-5140-8060

\section{REFERENCES}

1 World Health Organization. Global report on diabetes. Geneva, 2016. Available: http://apps.who.int/iris/bitstream/10665/204871/1/ 9789241565257 eng.pdf?ua=1 [Accessed 30 Mar 2020].

2 American Diabetes Association. 4. Comprehensive Medical Evaluation and Assessment of Comorbidities: Standards of Medical Care in Diabetes-2020. Diabetes Care 2020;43:S37-47.

3 American Diabetes Association. 10. Cardiovascular Disease and Risk Management: Standards of Medical Care in Diabetes-2020. Diabetes Care 2020;43:S111-34.

4 American Diabetes Association. 11. Microvascular Complications and Foot Care: Standards of Medical Care in Diabetes-2020. Diabetes Care 2020;43:S135-51.

5 American Diabetes Association. 9. Pharmacologic Approaches to Glycemic Treatment: Standards of Medical Care in Diabetes-2020. Diabetes Care 2020;43:S98-110.

6 Davies MJ, D'Alessio DA, Fradkin J, et al. Management of hyperglycemia in type 2 diabetes, 2018. A consensus report by the American diabetes association (ADA) and the European association for the study of diabetes (EASD). Diabetes Care 2018:41:2669-701.

7 Buse JB, Wexler DJ, Tsapas A, et al. 2019 update to: management of hyperglycemia in type 2 diabetes, 2018. A consensus report by the American diabetes association (ADA) and the European association for the study of diabetes (EASD). Diabetes Care 2020;43:487-93.

8 Cosentino F, Grant PJ, Aboyans V, et al. 2019 ESC guidelines on diabetes, pre-diabetes, and cardiovascular diseases developed in collaboration with the EASD. Eur Heart J 2020;41:255-323.

9 American Diabetes Association. 6. Glycemic Targets: Standards of Medical Care in Diabetes-2020. Diabetes Care 2020;43:S66-76.

10 Ali MK, Bullard KM, Saaddine JB, et al. Achievement of goals in U.S. diabetes care, 1999-2010. N Engl J Med 2013;368:1613-24.

11 Yokoyama H, Oishi M, Takamura $\mathrm{H}$, et al. Large-Scale survey of rates of achieving targets for blood glucose, blood pressure, and lipids and prevalence of complications in type 2 diabetes (JDDM 40). BMJ Open Diabetes Res Care 2016:4:e000294.

12 Blonde L, Aschner P, Bailey C, et al. Gaps and barriers in the control of blood glucose in people with type 2 diabetes. Diab Vasc Dis Res 2017:14:172-83

13 American Diabetes Association. 5. Facilitating Behavior Change and Well-being to Improve Health Outcomes: Standards of Medical Care in Diabetes-2020. Diabetes Care 2020;43:S48-65.
$14 \mathrm{He}$ X, Li J, Wang B, et al. Diabetes self-management education reduces risk of all-cause mortality in type 2 diabetes patients: a systematic review and meta-analysis. Endocrine 2017;55:712-31.

15 Liberati A, Altman DG, Tetzlaff J, et al. The PRISMA statement for reporting systematic reviews and meta-analyses of studies that evaluate health care interventions: explanation and elaboration. Ann Intern Med 2009;151:W65-94

16 Higgins JPT, Altman DG, Gøtzsche PC, et al. The Cochrane collaboration's tool for assessing risk of bias in randomised trials. BMJ 2011;343:d5928.

17 Davies M, Storms F, Shutler S, et al. Improvement of glycemic control in subjects with poorly controlled type 2 diabetes: comparison of two treatment algorithms using insulin Glargine. Diabetes Care 2005;28:1282-8.

18 Meneghini L, Koenen C, Weng W, et al. The usage of a simplified self-titration dosing guideline (303 Algorithm) for insulin detemir in patients with type 2 diabetes--results of the randomized, controlled PREDICTIVE 303 study. Diabetes Obes Metab 2007;9:902-13.

19 Garg SK, Admane K, Freemantle N, et al. Patient-led versus physician-led titration of insulin Glargine in patients with uncontrolled type 2 diabetes: a randomized multinational atlas study. Endocr Pract 2015;21:143-57.

20 Yale J-F, Berard L, Groleau M, et al. Titration: a randomized study to assess 2 treatment algorithms with new insulin Glargine 300 units/ $\mathrm{mL}$. Can J Diabetes 2017;41:478-84.

21 Russell-Jones D, Dauchy A, Delgado E, et al. Take Control: A randomized trial evaluating the efficacy and safety of self- versus physician-managed titration of insulin glargine $300 \mathrm{U} / \mathrm{mL}$ in patients with uncontrolled type 2 diabetes. Diabetes Obes Metab 2019;21:1615-24.

22 Bonadonna RC, Giaccari A, Buzzetti R, et al. Comparable efficacy with similarly low risk of hypoglycaemia in patient- vs physicianmanaged basal insulin initiation and titration in insulin-naïve type 2 diabetic subjects: the Italian titration approach study (ITAs). Diabetes Metab Res Rev.

23 Edelman SV, Polonsky WH. Type 2 diabetes in the real world: the elusive nature of glycemic control. Diabetes Care 2017;40:1425-32.

24 Blonde L, Brunton SA, Chava P, et al. Achievement of Target A1C $<7.0 \%$ ( $<53 \mathrm{mmol} / \mathrm{mol})$ by U.S. Type 2 Diabetes Patients Treated With Basal Insulin in Both Randomized Controlled Trials and Clinical Practice. Diabetes Spectr 2019;32:93-103.

25 Blonde L, Merilainen M, Karwe V, et al. Patient-directed titration for achieving glycaemic goals using a once-daily basal insulin analogue: an assessment of two different fasting plasma glucose targets - the TITRATE study. Diabetes Obes Metab 2009;11:623-31.

26 Philis-Tsimikas A, Brod M, Niemeyer M, et al. Insulin degludec oncedaily in type 2 diabetes: simple or step-wise titration (begin: once simple use). Adv Ther 2013;30:607-22.

27 Yu HM, Park KS, Hong JH, et al. Comparison of the efficacy and safety of insulin Detemir administered once daily according to two titration algorithms (3-0-3 and 2-4-6-8) in patients with type 2 diabetes mellitus. Endocrinol Metab 2020;35:142-8.

28 Yki-Järvinen $\mathrm{H}$, Juurinen L, Alvarsson $\mathrm{M}$, et al. Initiate insulin by aggressive titration and education (initiate): a randomized study to compare initiation of insulin combination therapy in type 2 diabetic patients individually and in groups. Diabetes Care 2007;30:1364-9.

29 Owens DR, S Bailey T, Fanelli CG, et al. Clinical relevance of pharmacokinetic and pharmacodynamic profiles of insulin degludec $(100,200 \mathrm{U} / \mathrm{mL})$ and insulin glargine $(100,300 \mathrm{U} / \mathrm{mL})$ - a review of evidence and clinical interpretation. Diabetes Metab 2019;45:330-40.

30 Blonde L, Khunti K, Harris SB, et al. Interpretation and impact of real-world clinical data for the practicing clinician. Adv Ther 2018;35:1763-74.

31 Davies M, Bain S, Charpentier G, et al. A randomized controlled, Treat-to-Target study evaluating the efficacy and safety of insulin Glargine $300 \mathrm{U} / \mathrm{mL}$ (Gla-300) administered using either DeviceSupported or routine titration in people with type 2 diabetes. $J$ Diabetes Sci Technol 2019;13:881-9.

32 Kim CS, Park SY, Kang JG, et al. Insulin dose titration system in diabetes patients using a short messaging service automatically produced by a knowledge matrix. Diabetes Technol Ther 2010;12:663-9.

33 Bee YM, Batcagan-Abueg APM, Chei C-L, et al. A smartphone application to deliver a Treat-to-Target insulin titration algorithm in Insulin-Naive patients with type 2 diabetes: a pilot randomized controlled trial. Diabetes Care 2016;39:e174-6. 